\title{
Evaluation of Antibacterial Activities of Tanzanian Moringa oleifera Extracts against Escherichia coli and Klebsiella pneumonia Clinical Isolates
}

\author{
Sartaz Begum ${ }^{1 *}$, Jenipher S. Asenga ${ }^{1}$, Valence M. K. Ndesendo ${ }^{1}$ and Baraka L. Ngingo ${ }^{2}$

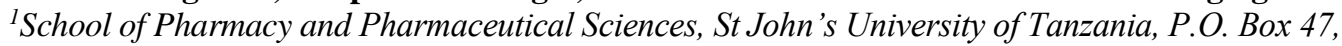 \\ Dodoma, Tanzania. \\ ${ }^{2}$ Biology Department, Faculty of Natural and Applied Sciences, St John's University of \\ Tanzania, P.O. Box 47, Dodoma, Tanzania. \\ ${ }^{*}$ Corresponding author, Email: sartaj0786@yahoo.com \\ Co-authors'e-mails: jenipherasenga@gmail.com; vndesendo@sjut.ac.tz; \\ baraka.ngingo@sacids.org
}

Received 13 Jan 2021, Revised 7 Jul 2021, Accepted 20 Jul 2021, Published Aug 2021

DOI: https://dx.doi.org/10.4314/tjs.v47i3.16

\begin{abstract}
In vitro antibacterial activities of methanolic leaf and seed extracts of Moringa oleifera grown in Dodoma, Tanzania were evaluated using standard microdilution and disc diffusion methods against extended spectrum beta lactamase producing Gram negative bacteria (Escherichia coli and Klebsiella pneumoniae). Microdilution method showed no activity at concentration of 20 $\mathrm{mg} / \mathrm{mL}$ for all the extracts except leaf extract which exhibited minimum inhibition at concentration of $2.5 \mu \mathrm{g} / \mathrm{mL}$ for $E$. Coli but when high concentrations of the extracts were used in the disc diffusion method then the results exhibited the highest killing susceptibility at concentration of 0.4 $\mathrm{g} / \mathrm{mL}$ with zone of inhibition $31 \mathrm{~mm}$ for leaf extract and $26 \mathrm{~mm}$ for seed extract against E. coli, and $27 \mathrm{~mm}$ for leaf extract and $29 \mathrm{~mm}$ for seed extract against K. pneumonia. Additionally, when both extracts were screened qualitatively for phytoconstituents using standard methods, leaf extract confirmed the presence of carbohydrates, cardiac glycosides, tannins and quinones, and seed extract confirmed the presence of proteins, carbohydrates, cardiac glycosides, alkaloids, terpenoids and quinones. These phytoconstituents can be new sources of future antibiotics that potentially combat the existing problem of antimicrobial resistance and thus, creating an awareness in the community regarding the usage of $M$. oleifera growing widely but neglected in Tanzania in spite of its nutritional values and traditional uses.
\end{abstract}

Keywords: Moringa oleifera, Phytoconstituents, Antibacterial activity, Escherichia coli and Klebsiella pneumoniae.

\section{Introduction}

Antimicrobial resistance has become a global threat to the public health worldwide. Mostly Gram negative bacteria are becoming resistant to commonly used antibiotics. Prevalence of extended spectrum for beta lactamase (ESBL) producing Klebsiella pneumoniae in clinical settings has been reported to be $45 \%$ to $80 \%$ in Tanzania (Moyo et al. 2010, Mawalla et al. 2011, Mshana et al. 2013) in addition to another very common ESBL-producing Gram negative bacteria Escherichia coli. Though little is known about the ESBL alleles in $K$. pneumoniae, causing neonatal sepsis, it is usually resistant to various antibiotics; therefore, the therapy is limited to very few expensive drugs which in most cases are not available and if available, are not 
affordable in developing countries like Tanzania (Mshana et al. 2013). In this regard, there is an urgent need to find alternative sources which can produce effective and easily affordable antibiotics that can combat the existing problem of antimicrobial resistance. In due course of search for alternative sources, traditional medicinal plants can be of worth investigation. Among the traditionally used plants, Moringa oleifera is considered as a miracle tree for its nutritional, medicinal and other valuable properties.

Moringa oleifera Lam is a fast growing, commonly cultivated drought resistant plant belonging to family Moringaceae, which is a single genus family comprising of 13 species (Saini et al. 2016). The plant is native to India and has been introduced and naturalized to the tropical and subtropical habitats around the globe (Leone et al. 2015). It is locally known as "mlonge" in Tanzania and is used in traditional folk medicine. $M$. oleifera is recognized for its vibrant and affordable sources of various phytochemicals with potential applications in food, medicines, water purification, animal feeds and biodiesel production among others (Daba 2016). All the plant parts, including leaves, immature pods, seeds, flowers and roots have been consumed by humans for a variety of applications and also hold ability to treat more than 300 diseases (Gupta et al. 2018). For example, the leaves can be consumed raw, dried or as an aqueous infusion to treat various ailments, including malaria, typhoid, parasitic diseases, arthritis, swellings, cuts, skin diseases, genito-urinary ailments, hypertension and diabetes. It has also been used to elicit lactation and boost the immune system (thus treating HIV/AIDS related symptoms) as well as act as cardiac stimulant and contraceptive remedy (Leone et al. 2015, Gandji et al. 2018). Though scientific based information for the above mentioned ailments is lacking, still there are published works on the specific uses like antiproliferation, hepatoprotective, antiinflammatory, antinociceptive, antiatherosclerotic, oxidative DNA damage protective, antiperoxidative, cardioprotective, antidyslipidemic,

anthelmintic, antihyperglycemic, antimicrobial, antioxidant, anti-ulcer and antiurolithiatic just to mention a few (Gandji et al. 2018). There have been increasing numbers of literature reviews which addressed cultivation, genetics, ethnopharmacology, phytochemistry, pharmacology, multiple biological activities among other properties of M. Oelifera (Leone et al. 2015, Daba 2016, Saini et al. 2016, Gupta et al. 2018, Gandji et al. 2018). In this regard, M. oleifera is considered as a "miracle tree" traditionally and scientifically.

Since this miracle plant has served a common link between the traditional and modern science and remained as a main source of medicaments through the centuries, where it also represents a rich source of antimicrobial agents, this study aimed at pursuing qualitative phytochemical analysis and investigation of in vitro antibacterial activities (against extended spectrum beta lactamase (ESBL) producing Gram negative bacteria $E$. coli and $K$. pneumoniae clinical isolates) of methanolic leaf and seed extracts of $M$. oleifera wildly growing but neglected in Tanzania. The study may also help the community to understand and increase the awareness about the potential benefits of $M$. oleifera which is affordable and widely available in the surrounding environment compared to the commercially available pricey medicines.

\section{Materials and Methods \\ Plant collection}

Fresh leaves and seeds from uninfected and healthy M. Oleifera tree were collected in March 2019 from Kikuyu area, Dodoma, Tanzania. Carefully hand plucked samples were placed in ziploc bags and transported safely to the Pharmaceutical laboratory at St John's University of Tanzania, and then air dried for two weeks at room temperature $\left(25-27{ }^{\circ} \mathrm{C}\right)$. The specimens were identified by a botanist and authenticated and preserved at the herbarium of the University. 


\section{Plant extraction}

The under-shade air dried, pulverized samples were soaked twice for 48 hours in methanol. The filtered crude extract was concentrated in vacuo using a rotatory evaporator while maintaining water bath temperature below 40 ${ }^{\circ} \mathrm{C}$ to avoid thermal decomposition of labile compounds. Later, the extract was taken to carry out experiments on antimicrobial activities.

\section{Phytochemical screening}

Phytochemical screenings of methanolic leaf and seed extracts of Moringa oleifera were carried out using standard procedures (Edeoga et al. 2005, Pradeep et al. 2014, Rajasudha and Manikandan 2019) and were conducted at the Pharmaceutical laboratory of St John's University of Tanzania.

Test for alkaloids (Wagner's test): Both the extracts were treated with few drops of Wagner's reagent $(0.5 \mathrm{~g}$ of iodine and $1.5 \mathrm{~g}$ of potassium iodide were dissolved in $5 \mathrm{~mL}$ of distilled water and the solution was diluted to $20 \mathrm{~mL}$ using water). The formation of reddish brown precipitate indicated the presence of alkaloids.

Test for terpenoids (Salkowki's test): Extracts were dissolved in $2 \mathrm{~mL}$ of chloroform and treated with $2 \mathrm{~mL}$ of concentrated sulphuric acid to form a layer. Reddish brown colouration at the interface indicated presence of terpenoids.

Test for flavonoids (alkaline reagent test): Extracts were treated with few drops of $20 \%$ sodium hydroxide solution. Formation of an intense yellow colour, which turns colourless on addition of dilute hydrochloric acid, indicates the presence of flavonoids.

Test for tannins (Braymer's test): Extracts were boiled with $20 \mathrm{~mL}$ of distilled water and then filtered. The filtrates were treated with $10 \%$ alcoholic ferric chloride solution and formation of brownish green to blue-black colour indicated presence of tannins.

Test for cardiac glycosides (Keller Kiliani's test): The extracts were dissolved in $4 \mathrm{~mL}$ of distilled water and then treated with $2 \mathrm{~mL}$ of glacial acetic acid containing few drops of ferric chloride solution. Further, $2 \mathrm{~mL}$ of concentrated sulphuric acid was added carefully without mixing the solution. Formation of a brown ring at the interface indicated the presence of deoxysugars (characteristics of cardenolides).

Test for carbohydrates (Benedict's test): Extracts were treated with Benedict's reagent (cupric citrate complex) and heated gently. Formation of orange-red/brick red/rusty brown precipitate indicated presence of reducing sugars.

Test for proteins (Biuret test): Extracts were dissolved in $4 \mathrm{~mL}$ of distilled water and then treated with an equal volume of $1 \%$ sodium hydroxide solution followed by 3 drops of aqueous copper (II) sulphate solution. A colour change from blue to purple/violet indicated presence of proteins.

Test for quinones: Extracts were treated with concentrated hydrochloric acid. Formation of yellow colouration or precipitate indicated the presence of quinones.

\section{Antibacterial assays \\ Microplate dilution method}

The investigation of antimicrobial activities of $M$. oleifera extracts was done by broth microdilution technique using sterile flat bottomed 96 well polystyrene microtitre plates (Begum et al. 2020). The assay was carried out at the Biology laboratory, Faculty of Natural and Applied Sciences, St John's University of Tanzania. Escherichia coli (ATCC 25922) and Klebsiella pneumoniae (ATCC 700603) were used as representatives of extended spectrum beta-lactamase (ESBL) producing bacteria for the determination of antibacterial activities.

Test solutions were prepared by dissolving $20 \mathrm{mg}$ of extracts in $0.1 \mathrm{~mL}$ of DMSO and diluted with $0.9 \mathrm{~mL}$ of broth to make a concentration of $20 \mathrm{mg} / \mathrm{mL}$. Then $50 \mu \mathrm{L}$ of the test solution were pipetted and added into the first well of each row of plates which preloaded with $50 \mu \mathrm{L}$ of broth. Then serial dilution of concentrations $10,5,2.5,1.25,0.625,0.312$, 0.156 and $0.078 \mu \mathrm{g} / \mathrm{mL}$ were performed by 
transferring the test sample from the first row wells to wells of the next rows, down to the last rows. This was followed by addition of $50 \mu \mathrm{L}$ of the solution containing the test organisms (0.5 McFarland dilutions) to each of the wells. Wells in two columns were used as growth controls, while other two were used for cefotaxime $(1 \mathrm{~g} / \mathrm{mL})$ as positive control for antibacterial activities. DMSO solvent to which extracts were dissolved was used as a negative control. The microtitre plates were incubated at $37{ }^{\circ} \mathrm{C}$ for 24 hours. After the incubation period, $30 \mu \mathrm{L}$ of a $0.2 \% p$-iodonitrotetrazolium chloride (INT) was added to the wells followed by incubation at $37{ }^{\circ} \mathrm{C}$ for $30 \mathrm{~min}$. Presence of microbial growth was indicated by change of INT colour to pink, while absence of growth was indicated as no colour change (the colourless tetrazolium salt acted as an electron acceptor and reduced to a pink coloured formazan product by a biologically active organism). The lowest concentration at which microbial growth inhibited was recorded as the minimum inhibitory concentration (MIC).

\section{Disk diffusion method}

Investigations of antibacterial activities were carried out using a standard disk diffusion method (Adhikari et al. 2013) at Microbiology lab, Dodoma Regional Referral Hospital, Dodoma, Tanzania. Bacterial strains were isolated, cultured and inoculated into Mueller Hinton agar plates and incubated at $37{ }^{\circ} \mathrm{C}$ for $24 \mathrm{hrs}$ and then identified and stored under appropriate conditions for further processing. A Whatman filter paper number 1 (round shape of $5 \mathrm{~mm}$ in diameter) was used to prepare the disk because of its high loading capacity and particle retention. The disks were solubilized/immersed into the $M$. oleifera leaf and seed extracts at concentrations of $0.4 \mathrm{~g} / \mathrm{mL}$, $0.3 \mathrm{~g} / \mathrm{mL}$ and $0.2 \mathrm{~g} / \mathrm{mL}$ for $24 \mathrm{hrs}$. The disks were then placed on the agar plates containing bacteria of interest and standard antibiotics as reference drugs. The plates were incubated at $37{ }^{\circ} \mathrm{C}$ for $24 \mathrm{hrs}$ prior to determination of results, followed by measuring the zone of inhibition in millimetres by using a ruler. The diameter of the zone of inhibition was related to the susceptibility of the isolate. The zone diameters of the disk containing the extract and a standard control drug were interpreted using the criteria published by the Clinical and Laboratory Standards Institute (CLSI 2012).

\section{Results and Discussion \\ Phytochemical composition}

The results of phytochemical screening of the methanolic leaf and seed extracts of $M$. oleifera are presented in Table 1 which depicted the presence of cardiac glycosides, carbohydrates, tannins and quinones and absence of alkaloids, terpenoids, flavonoids and proteins in methanolic leaf extract, andthe presence of alkaloids, terpenoids, cardiac glycosides, carbohydrates, proteins and quinones and absence of flavonoids and tannins in methanolic seed extract when analyzed qualitatively.

Table 1: Qualitative analysis of phytochemicals found in methanolic leaf and seed extracts of Moringa oleifera

\begin{tabular}{lcc}
\hline $\begin{array}{l}\text { Chemical } \\
\text { constituents }\end{array}$ & Leaf extract & $\begin{array}{c}\text { Seed } \\
\text { extract }\end{array}$ \\
\hline Alkaloids & - & + \\
Terpenoids & - & + \\
Flavonoids & - & - \\
Tannins & + & - \\
Cardiac glycosides & + & + \\
Carbohydrates & + & + \\
Proteins & - & + \\
Quinones & + & + \\
\hline
\end{tabular}

Key: + present, - absent

The rapid discovery of various medicinal plants with different classes of natural products (secondary metabolites) has provided a remarkable intervention in history. The presence of secondary metabolites in medicinal plants has been linked with antimicrobial properties of crude plant extracts (Compean and Ynalvez 2014). The screening of phytochemicals in $M$. oleifera revealed the presence of cardiac glycosides, carbohydrates, tannins, quinones, alkaloids, terpenoids and proteins (Table 1) and these phytochemicals have the ability to inactivate microbial 
adhesions, thus inhibiting the growth of various bacterial strains. However, results of the present study indicated lack of alkaloids in the leaf extract of $M$. oleifera which is in line with the literature review (Fahal et al. 2018), but alkaloids were present in seed extract of the same plant. Literature review reported the presence of flavonoids (AbdRani et al. 2018), while the investigated species growing in Dodoma, Tanzania lacked flavonoids in both the leaf and seed extracts. The difference may be due to the geographical location and environmental conditions of the investigated plant species.

\section{Antibacterial activities}

Assessments of antibacterial activities of the Moringa oleifera leaf and seed extracts were carried out using the standard microplate dilution method against extended spectrum $\beta$ lactamase (ESBL) producing bacteria Escherichia coli and Klebsiella pneumoniae. Results were evaluated using minimum inhibition concentrations (MIC values, $\mathrm{mg} / \mathrm{mL}$ ) and tabulated in Table 2. As the results of microdilution method showed no activity except leaf extract which exhibited $2.5 \mu \mathrm{g} / \mathrm{mL}$ for $E$. coli, standard disc diffusion method was carried out at higher concentrations to evaluate the antibacterial activities of the $M$. oleifera leaf and seed extracts using ESBL producing bacteria E. coli and K. Pneumoniae which were isolated from the neonates suffering from sepsis in Dodoma Regional Referral Hospital and then cultured. Results were evaluated using zones of inhibition in millimetres and tabulated in Table 3.

Table 2: Antibacterial test results of $M$. oleifera leaf and seed extracts against $E$. coli and $K$. pneumoniae using minimum inhibition concentrations (MIC values, $\mu \mathrm{g} / \mathrm{mL}$ )

\begin{tabular}{lll}
\hline Plant part/ & MIC values $(\mu \mathrm{g} / \mathrm{mL})$ & \\
\cline { 2 - 3 } Standard drug & Escherichia coli & Klebsiella pneumoniae \\
\hline Leaves & 2.5 & No activity \\
Seeds & No activity & No activity \\
DMSO & 5 & 5 \\
Cefotaxime $(1 \mathrm{~g} / \mathrm{mL})$ & $<0.078$ & $<0.078$ \\
\hline
\end{tabular}

Table 3: Antibacterial susceptibility test results of $M$. oleifera leaf and seed extracts against $E$. coli and $K$. pneumoniae using zone of inhibition (ZOI)

\begin{tabular}{|c|c|c|c|c|}
\hline \multirow[t]{2}{*}{ Concentration $(\mathrm{g} / \mathrm{ml})$} & \multicolumn{2}{|c|}{ ZOI against $E$. coli $(\mathrm{mm})$} & \multicolumn{2}{|c|}{ ZOI against $K$. pneumoniae $(\mathrm{mm})$} \\
\hline & Leaves & Seeds & Leaves & Seeds \\
\hline $0.4 \mathrm{~g} / \mathrm{mL}$ & 31 & 26 & 27 & 29 \\
\hline $0.3 \mathrm{~g} / \mathrm{mL}$ & 27 & 20 & 24 & 22 \\
\hline $0.2 \mathrm{~g} / \mathrm{mL}$ & 20 & 15 & 19 & 18 \\
\hline Nitrofurantoin $(300 \mu \mathrm{g})$ & 20 & 20 & 18 & 18 \\
\hline Gentamycin $(10 \mu \mathrm{g})$ & 22 & 22 & 21 & 21 \\
\hline Ciprofloxacin $(30 \mu \mathrm{g})$ & 32 & 32 & 27 & 27 \\
\hline Penicillin $(10 \mu \mathrm{g})$ & 19 & 19 & 19 & 19 \\
\hline
\end{tabular}

The ZOI of $M$. oleifera extracts at concentrations of $0.4 \mathrm{~g} / \mathrm{mL}, 0.3 \mathrm{~g} / \mathrm{mL}$, and 0.2 $\mathrm{g} / \mathrm{mL}$, and for the positive controls nitrofurantoin $(300 \mu \mathrm{g})$, gentamycin $(10 \mu \mathrm{g})$, ciprofloxacin $(30 \mu \mathrm{g})$ and penicillin $(10 \mu \mathrm{g})$ were $31,27,20,20,22,32$ and $19 \mathrm{~mm}$, respectively for leaves and 26, 20, 15, 20, 22,
32 and $19 \mathrm{~mm}$, respectively for seeds against $E$. coli. The ZOI of $M$. oleifera extracts at concentrations of $0.4 \mathrm{~g} / \mathrm{mL}, 0.3 \mathrm{~g} / \mathrm{mL}$ and 0.2 $\mathrm{g} / \mathrm{mL}$, and for the positive controls nitrofurantoin $(300 \mu \mathrm{g})$, gentamycin $(10 \mu \mathrm{g})$, ciprofloxacin $(30 \mu \mathrm{g})$ and penicillin $(10 \mu \mathrm{g})$ were $27,24,19,18,21,27$ and $19 \mathrm{~mm}$, 
respectively for leaves and 29, 22, 18, 18, 21, 27 and $19 \mathrm{~mm}$ respectively for seeds against $K$. pneumoniae. The extracts with concentration of $0.4 \mathrm{~g} / \mathrm{mL}$ showed the highest killing susceptibility (Table 3 ) though not potent as that of positive standards, still the antibiogram of microorganisms exposed to methanolic extracts of $M$. oleifera showed susceptibility to all the bacterial strains. The present results for ZOI of the methanolic leaf extract exhibited against K. Pneumoniae $(27 \mathrm{~mm})$ are in agreement with Kamath et al. (2016) and Fouad et al. (2019) who reported the ZOI of $M$. oleifera ethanolic leaf extract to be $21 \mathrm{~mm}$ and $28.5 \mathrm{~mm}$, respectively. Moreover, the present results for ZOI of the leaf extract exhibited against E. coli $(31 \mathrm{~mm})$ are also in agreement with reports of Fouad et al. (2019) who reported ZOI of $27.75 \mathrm{~mm}$ and but does not comply with Amabye and Tadesse (2016) who reported ZOI to be $8 \mathrm{~mm}$. Furthermore, Abraham and Okon (2014) reported the ZOI of $M$. oleifera acetone leaf extract to be $12 \mathrm{~mm}$ against $K$. pneumoniae and $9 \mathrm{~mm}$ against $E$. coli and were sensitive according to the NCCLS standard. Additionally, present results of seed extracts exhibited against $K$. Pneumoniae (ZOI $29 \mathrm{~mm}$ ) and E. coli (ZOI 26 $\mathrm{mm})$ were in agreement though with slight differences with reports of Emmanuel et al. (2014) for both bacterial species and with Walter et al. (2011) for E. coli species. The difference in bacterial response was possibly due to the nature of the bacterial species, solvent and the concentrations used. The medium of extraction of $M$. oleifera seemed to have an impact on the potency of the active principles which produced wider zones of inhibition, and another factor may be the synergistic effects between methanol and the active principles of the investigated plant.

\section{Conclusion}

The findings in the present study support the traditional use of $M$. oleifera and represent an economic and safe alternative drug for the treatment of bacterial infections caused by ESBL producing Gram negative bacteria at concentration of $0.4 \mathrm{~g} / \mathrm{mL}$ for both the extracts. Though people worldwide are using raw and processed M. oleifera parts, still clinical trials against bacterial infections and a study on metabolic interchanges in bacterial metabolic pathways should be conducted. Moreover, isolation of the secondary metabolites from the leaf and seed extracts can be helpful in future research and development of pharmaceutical products in Tanzania, and in vitro study demonstrated that traditional medicine can be as effective as modern medicine to combat human pathogenic bacteria. Thus, the results of this study filled the knowledge gaps and also opened doors for further research and can develop avenues for better valorization in Tanzania.

\section{Acknowledgements}

Authors greatly acknowledge the laboratory personnel at the Dodoma Region Referral Hospital for providing lab facilities and the bacterial strains for assessing antibacterial activities.

Conflict of Interest: Authors declare no conflict of interest.

\section{References}

AbdRani NZ, Husain K and Kumolosasi E 2018 Moringa genus: a review of phytochemistry and pharmacology. Front. Pharmacol. 9 (article 108): 1-26.

Abraham NA and Okon OG 2014 Antibacterial effect of Moringa oleiferaextracts on bacteria associated with urinary tract infection. Int. J. Res. 1(8): 1308-1316.

Adhikari SR, Pant B and Pokhrel K 2013 Antimicrobial Activity of Chemical Compounds from invivo roots and invitro callus of Withania somnifera (L.) Dunal. Biomed. Biotechnol. 1: 21-26.

Amabye TG and Tadesse FM 2016 Phytochemical and antibacterial activity of Moringa oleifera available in the market of Mekelle. J. Anal. Pharm. Res. 2:1-4.

Begum S, Munissi JJE, Buriyo AS, Makangara JJ, Lucantoni L, Avery VM, Erdelyi M and Nyandoro SS 2020 Antiplasmodial, antimicrobial and cytotoxic activities of 
extracts from selected medicinal plants growing in Tanzania. J. Biol. Active Prod. Nat.10(2): 165-176.

CLSI (Clinical and Laboratory Standards Institute) 2012 Performance standards for antimicrobial disk susceptibility testing: $11^{\text {th }}$ ed. Available http://antimicrobianos.com.ar/ATB/wpcontent/uploads/2012/11/01-CLSI-M02-A112012.

Compean KL and Ynalvez RA 2014 Antimicrobial Activity of plant secondary metabolites: a review. Res. J. Med. Plants 8: 204-213.

Daba M 2016 Miracle tree: a review on multipurposes of Moringa oleifera and its implication for climate change mitigation. $J$. Earth Sci. Clim. Change 7: 366-371.

Edeoga H, Okwu D and Mbaebie B 2005 Phytochemical constituents of some Nigerian medicinal plants. Afr. J. Biotechnol. 4: 685688.

Emmanuel SA, Olajide OO, Abubakar S, Idowu ID, Orishadipe ATand Thomas SA 2014 phytochemical and antimicrobial studies of methanol, ethyl acetate, and aqueous extracts of Moringa oleifera Seeds. Am. J. Ethnomed. 1(5): 346-354.

Fahal EM, Saharan N, BabithaRani AM, Aklakur MD and Chanu TI 2018 Qualitative analysis of some important phytochemical constituents of Moringa oleifera (Lam) leaves and seeds. Int. J. Chem. Stud. 6: 648-650.

Fouad EA, Elnaga ASMand Kandil MM 2019 Antibacterial efficacy of Moringa oleifera leaf extract against pyogenic bacteria isolated from a dromedary camel (Camelus dromedarius) abscess. Vet.World 12: 802-808.

Gandji K, Chadare FJ, Idohou R, Salako VK, Assogbadjo AE and Kakai RG 2018 Status and utilisation of Moringa Oleifera Lam: a review. Afr. Crop Sci. J.26: 137-156.

Gupta S, Jain R, Kachhwaha S and Kothari SL 2018 Nutritional and medicinal applications of Moringa oleifera Lam. Review of current status and future possibilities. J. Herb. Med. 11:1-11.

Kamath N, Swaminathan R and Desai N 2016 Antibacterial activity of Indian medicinal plant Moringa oleifera against MRSA and Klebsiella Spp. (ESBL) which are commonly isolated bacteria in hospital environments. Int. J. Appl. Res. 2(8): 515-517.

Leone A, Spada A, Battezzati A, Schiraldi A, Aristil J and Bertoli S 2015 Cultivation, genetic, ethnopharmacology, phytochemistry and pharmacology of Moringa oleifera leaves: An Overview. Int. J. Mol. Sci. 16: 1279112835.

Mawalla B, Mshana SE, Chalya PL, Imirzalioglu C and Mahalu W 2011 Predictors of surgical site infections among patients undergoing major surgery at Bugando Medical Centre in North-western Tanzania.BMC Surg. 11: 21.

Moyo SJ, Aboud S, Kasubi M, Lyamuya EF and Maselle SY 2010 Antimicrobial resistance among producers and non-producers of extended spectrum beta-lactamases in urinary isolates at a tertiary Hospital in Tanzania. BMC Res. Notes 3(1): 348.

Mshana SE, Hain T, Domann E, Lyamuya EF, Chakraborty T and Imirzalioglu C 2013 Predominance of Klebsiella pneumoniae ST14 carrying CTX-M-15 causing neonatal sepsis in Tanzania. BMC Infectious Diseases 13: 466

Pradeep A, Dinesh M, Govindaraj A, Vinothkumar D and Rameshbabu NG2014 Phytochemical analysis of some important medicinal plants. Int. J. Biol. Pharm. Res.5: 48-50.

Rajasudha V and Manikandan R 2019 Phytochemical screening and Highperformance liquid chromatography (HPLC) profile of different extracts of Euphorbia hirta (Linn). J. Pharmacogn. Phytochem.8: 45-50.

Saini RK, Sivanesan I and Keum YS2016 Phytochemicals of Moringa oleifera: a review of their nutritional, therapeutic and industrial significance. 3 Biotech. 6: 203.

Walter A, Samuel W, Peter A and Joseph O 2011 Antibacterial activity of Moringa oleifera and Moringa stenopetala methanol and n-hexane seed extracts on bacteria implicated in water borne diseases.Afr. J. Microbiol. Res. 5: 153157. 